\title{
Reliability and Validity of the Ukrainian Version of the Young Schema Questionnaire - Short Form 3 (YSQ-S3)
}

\author{
Soorena Sardarzadeh \\ Department of Psychodiagnostics and Clinical Psychology, Faculty of Psychology, Taras Shevchenko National University, Kyiv, Ukraine \\ Email address: \\ Soorena.sardarzadeh@gmail.com

\section{To cite this article:} \\ Soorena Sardarzadeh. Reliability and Validity of the Ukrainian Version of the Young Schema Questionnaire - Short Form 3 (YSQ-S3). \\ Advances in Sciences and Humanities. Vol. 4, No. 4, 2018, pp. 56-61. doi: 10.11648/j.ash.20180404.11
}

Received: August 14, 2018; Accepted: November 1, 2018; Published: November 29, 2018

\begin{abstract}
Objective: This study aims to investigated the reliability and validity of the Ukrainian version of third version of the Young Schema Questionnaire (YSQ-S3; Young, 2005) and provide expected scores for nonclinical samples. Method: The latest version of the questionnaire, the YSQ-S3, has received little attention, and its Ukrainian adaptation has yet to be validated. The participants were 1200 nonclinical persons of both gender, male $(55 \%)$ and female $(45 \%)$. The majority of participants had a bachelor's degree, which includes 31\% of the statistical sample. The Young Schema Questionnaire assesses early maladaptive schemas (EMSs) and schema domains. This study performed reliability analysis, confirmatory factor analysis, and second and third-order confirmatory factor analysis. TheYSQ-S3 proved to be reliable and corresponded to the theoretically proposed 18-dimensional structure. Results: Schema scores were positively associated with measures of psychopathology and personality disorder, indicating convergent validity. The results of the study showed that due to the Cronbach's alpha that is higher than 0.7 , the reliability of all variables is desirable. Confirmatory factor analyses support the schema domains. We conclude that the YSQ-S3 is a psychometrically sound instrument that can be used Ukraine in research on early maladaptive schemas. Further research is necessary particularly in larger clinical samples.
\end{abstract}

Keywords: Early Maladaptive Schema, Young Schema Questionnaire, Reliability, Validity

\section{Introduction}

Schema therapy is a psychotherapy approach combining traditional cognitive-behavioral therapy with elements of psychodynamic approaches, Gestalt therapy, and humanistic therapies [1]. It recently gained increased attention, since outcome studies demonstrated its efficacy and effectiveness in patients with personality disorders, mainly borderline personality disorder [2-6]. Central to schema therapy is the concept of early maladaptive schemas (EMS), thought to develop in childhood when essential needs of the child remain unmet. ). Schemas are patterns which when they are triggered make the person feel intense emotions. This includes memories, physical sensations and cognition. According to Young's theory, a combination of the four can cause early maladaptive schemas. According to Young, there are types of early childhood experiences that can cause a child to have schemas. These are the following:

1. The child who does not get his/her core needs met. The child needed affection, empathy and guidance but didn't get it etc.

2. The child who is traumatized or victimized by a very domineering, abusive or highly critical parent.

3. The child who learns primarily by internalizing the parent's voice. Every child internalizes or identifies with both parents and absorbs certain characteristics of both parents, so when the child internalizes the punitive punishing voice of the parent and absorbs the characteristics they become schemas.

4. The child who receives too much of a good thing. The child who is overprotected, over indulged or given an excessive degree of freedom and autonomy without any limits being set.

EMS are usually assessed with self-report questionnaires, mainly the Young Schema Questionnaire (YSQ). The original version of this instrument was developed by Young (1990) to assess 16 schemas. It consists of 205 items, and it was shown to be reliable and valid in large clinical and student samples [7]. Based on the findings of Schmidt et al. [7], Young and Brown (1994) developed a short form of the YSQ comprising five items 
for each of the 16 EMS. The short form of the YSQ has been revised repeatedly. In its latest form, the YSQ-S3, it comprises 90 items and there are five domains or themes in which the 18 schemas fall under [8]. The first domain is disconnection and rejection which includes the following schemas: mistrust/abuse, abandonment/instability, defectiveness/shame and social isolation/alienation. These are results of abusive or traumatic childhood experiences. The child usually comes from an unstable family [9]. The second domain is impaired autonomy and performance, which includes dependence or incompetence, vulnerability to harm, enmeshment and failure. Impaired autonomy and performance is a result of over protectiveness or neglect of the parents which results in the child feeling incompetent or dependent [9]. The third domain is impaired limits, which includes entitlement and insufficient selfcontrol/self-discipline. In this, the internal self-control of the child was not developed because the family sets no boundaries on children. As the child did not have rules he then feels a sense of entitlement, and/or will not develop self-control [9]. The fourth is other directedness which includes subjugation, selfsacrifice and approval seeking or recognition seeking. In this, the child experiences conditional love or that the family is concerned with self-image. The pa- rents may also be too involved with themselves that the child then continuously seeks approval and recognition [9]. The fifth is over-vigilance and inhibition, which includes negativity, emotional inhibition, unrelenting standards/hypocriticalness and punitiveness. Here the parents are strict and controlling. The child then becomes emotionally inhibited, pessimistic and extremely critical [9].

\section{Method}

\subsection{Demographic Information}

Results of demographic study indicated that out of 1200 people as statistical sample, 55 percent were male and 45 percent were female. Respondent's average age was 19-54 years old. Most of them including 31 percent had bachelor degree. TheYSQ-S3 [10] is a self-report instrument. People are asked to describe themselves by rating descriptive statements through a 6-step Likert-type response format ranging from completely untrue of me to describe me perfectly. Higher values indicate a stronger presence of the respective schema. The YSQ-S3 assesses 18 EMS (see Table 1) with five items per scale, resulting in a total of 90 items.

Table 1. Schemas, schema domains, and associated needs.

\begin{tabular}{lll}
\hline Schema domains & Associated needs & Schemas \\
\hline $\begin{array}{l}\text { Disconnection } \\
\begin{array}{l}\text { Impaired autonomy and } \\
\text { achievement }\end{array}\end{array}$ & $\begin{array}{l}\text { Safe attachment, acceptance, nurturing, } \\
\text { protection }\end{array}$ & $\begin{array}{l}\text { Emotional deprivation Abandonment/Instability Mistrust/Abuse Social } \\
\text { isolation/Alienation Defectiveness/Shame Impaired autonomy and } \\
\text { achievement }\end{array}$ \\
$\begin{array}{l}\text { Impaired limits } \\
\begin{array}{l}\text { Other-directedness } \\
\text { inhibgerated vigilance and }\end{array}\end{array}$ & Autonomy, competency, identity & $\begin{array}{l}\text { Failure to achieve Dependence/Incompetence Vulnerability to harm or } \\
\text { illness Enmeshment/Undeveloped self }\end{array}$ \\
& Free expression of needs and emotions & Entitlement/Grandiosity Insufficient self-control \\
Subjugation Self-sacrifice Approval-seeking \\
Emotional inhibition Unrelenting standards Negativity/Pessimism \\
\hline
\end{tabular}

\subsection{Studying Reliability of Tools}

In order to study reliability of tools Cronbach alpha was used. Results of the study indicated that tools are reliable because Cronbach alpha is bigger than $0 / 7$.

Table 2. Reliability of the tools.

\begin{tabular}{|c|c|c|c|c|}
\hline Variable & abbreviation & mean & Standard deviation & Cronbach alpha \\
\hline Abandonment/Instability & A.I & 2.1503 & 1.13599 & 0.845 \\
\hline Mistrust/Abuse & M.A & 2.9947 & 1.30025 & 0.911 \\
\hline Emotional Deprivation & ED & 2.7778 & 1.23123 & 0.877 \\
\hline Defectiveness/Shame & D.S & 2.5668 & 1.17324 & 0.902 \\
\hline Social Isolation/Alienation & S.A & 2.0715 & 1.05169 & 0.915 \\
\hline Dependence/Incompetence & D.I & 2.3427 & 1.16801 & 0.888 \\
\hline Vulnerability to Harm or Illness & VH & 2.1632 & 1.06396 & 0.779 \\
\hline Enmeshment/Undeveloped & E.U & 2.3540 & 1.15917 & 0.794 \\
\hline Failure & FA & 2.3070 & 1.15149 & 0.902 \\
\hline Entitlement/Grandiosity & E.G & 2.4498 & 1.14882 & 0.945 \\
\hline Insufficient Self-Control/Self-Discipline & I.S & 3.6278 & 1.19138 & 0.977 \\
\hline Subjugation & SU & 2.8837 & 1.33939 & 0.815 \\
\hline Self-Sacrifice & SS & 3.5342 & 1.33953 & 0.854 \\
\hline Approval-Seeking/Recognition-Seeking & A.R & 3.1458 & 1.27485 & 0.872 \\
\hline Negativity/Pessimism & N.P & 3.0278 & 1.29797 & 0.914 \\
\hline Emotional Inhibition & EI & 3.4488 & 1.35062 & 0.798 \\
\hline Unrelenting Standards/Hypercriticalness & U.H & 2.9552 & 1.33346 & 0.827 \\
\hline Punitiveness & $\mathrm{PU}$ & 3.0975 & 1.20194 & 0.941 \\
\hline
\end{tabular}




\subsection{Validity of the Tools}

In order to approve validity, structural equation approach was used by AMOS software. First, for investigating validity of the structure, first and second order Confirmatory Factor Analysis was used. Finally, for studying final model fitting, model fit indices were used. The model is as figure 1. In this model, 24 latent variables are observed, explained and measure by 90 variables.

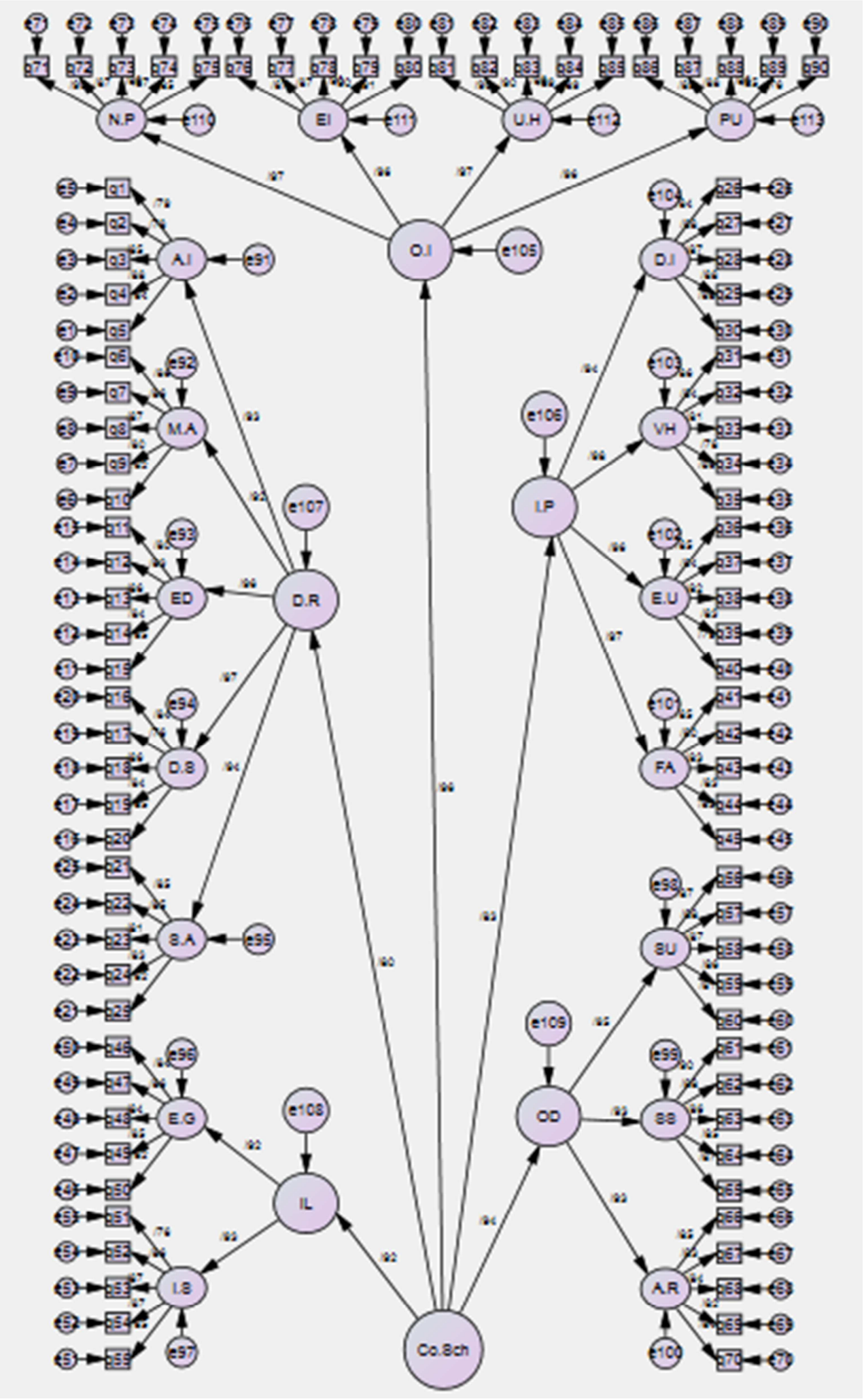

Figure 1. Designed model in the software. 


\section{Results}

Descriptive Statistic

Results of descriptive statistic indicated that Abandonment/Instability with 2.1503 mean, Mistrust/Abuse with 2.9947 mean, Emotional Deprivation with 2.7778 mean, Defectiveness/Shame with 2.5668 mean, Social Isolation/Alienation with 2.0715 mean, Dependence/Incompetence with 2.3427 mean, Vulnerability to Harm or Illness with 2.1632 mean, Enmeshment/Undeveloped with 2.3540 mean, Failure with
2.3070 mean, Entitlement/Grandiosity with 2.4498 mean, Insufficient Self-Control/Self-Discipline with 3.6278 mean, Subjugation with 2.8837 mean, Self-Sacrifice with 3.5342 mean, Approval-Seeking/Recognition-Seeking with 3.1458 mean, Negativity/Pessimism with 3.0278 mean, Emotional Inhibition with 3.4488 mean, Unrelenting Standards/Hypercriticalness with 2.9552 mean and Punitiveness with 3.0975 mean are reported.

Results of Confirmatory Factor Analysis in table 3 are reported.

Table 3. First order Confirmatory Factor Analysis.

\begin{tabular}{|c|c|c|c|c|c|c|c|c|c|c|c|c|c|}
\hline & & & Estimate & S.E. & C.R. & $\mathbf{P}$ & & & & Estimate & S.E. & C.R. & $\mathbf{P}$ \\
\hline q5 & $<---$ & A.I & $/ 836$ & & & & q50 & $<---$ & E.G & $/ 823$ & & & \\
\hline q4 & $<---$ & A.I & $/ 880$ & $/ 027$ & $38 / 932$ & - & q49 & $<---$ & E.G & $/ 845$ & $/ 025$ & $35 / 347$ & - \\
\hline q3 & $<---$ & A.I & $/ 853$ & $/ 027$ & $36 / 949$ & - & $\mathrm{q} 48$ & $<---$ & E.G & $/ 836$ & $/ 028$ & $34 / 715$ & - \\
\hline q2 & $<---$ & A.I & 1776 & $/ 023$ & $31 / 924$ & - & $\mathrm{q} 47$ & $<---$ & E.G & $/ 857$ & $/ 024$ & $36 / 108$ & - \\
\hline q1 & $<---$ & A.I & $/ 795$ & $/ 025$ & $33 / 075$ & - & $q 46$ & $<---$ & E.G & $/ 844$ & $/ 024$ & $35 / 239$ & - \\
\hline $\mathrm{q} 10$ & $<---$ & M.A & $/ 818$ & & & & q55 & $<---$ & I.S & $/ 855$ & & & \\
\hline q9 & $<---$ & M.A & $/ 804$ & $/ 030$ & $32 / 647$ & - & q54 & $<---$ & I.S & $/ 867$ & $/ 027$ & $39 / 561$ & - \\
\hline q8 & $<---$ & M.A & $/ 870$ & $/ 030$ & $36 / 803$ & - & q53 & $<---$ & I.S & $/ 870$ & $/ 025$ & $39 / 754$ & - \\
\hline q7 & $<---$ & M.A & $/ 855$ & $/ 030$ & $35 / 824$ & - & q52 & $<---$ & I.S & $/ 858$ & $/ 025$ & $38 / 845$ & - \\
\hline q6 & $<---$ & M.A & $/ 858$ & $/ 029$ & $36 / 019$ & - & q51 & $<---$ & I.S & $/ 763$ & $/ 028$ & $31 / 935$ & - \\
\hline q15 & $<---$ & ED & $/ 855$ & & & & q56 & $<---$ & SU & $/ 875$ & & & \\
\hline q14 & $<---$ & ED & $/ 842$ & $/ 026$ & $37 / 952$ & - & q57 & $<---$ & SU & $/ 876$ & $/ 024$ & $42 / 785$ & - \\
\hline q13 & $<---$ & ED & 1857 & $/ 024$ & $39 / 104$ & - & q58 & $<---$ & SU & $/ 871$ & $/ 022$ & $42 / 205$ & - \\
\hline $\mathrm{q} 12$ & $<---$ & ED & 1829 & $/ 024$ & $36 / 864$ & - & q59 & $<---$ & SU & $/ 859$ & $/ 023$ & $41 / 109$ & - \\
\hline q11 & $<---$ & ED & $/ 805$ & $/ 025$ & $35 / 081$ & - & q60 & $<---$ & SU & $/ 814$ & $/ 024$ & $37 / 055$ & - \\
\hline q20 & $<---$ & D.S & $/ 846$ & & & & q61 & $<---$ & SS & $/ 895$ & & & \\
\hline q19 & $<---$ & D.S & 1839 & $/ 024$ & $37 / 138$ & - & $\mathrm{q} 62$ & $<---$ & SS & $/ 884$ & $/ 022$ & $45 / 915$ & - \\
\hline q18 & $<---$ & D.S & $/ 855$ & $/ 027$ & $38 / 386$ & - & $q 63$ & $<---$ & SS & $/ 856$ & $/ 020$ & $42 / 718$ & - \\
\hline q17 & $<---$ & D.S & $/ 757$ & $/ 031$ & $31 / 457$ & - & q64 & $<---$ & SS & $/ 849$ & $/ 022$ & $41 / 909$ & - \\
\hline q16 & $<---$ & D.S & $/ 836$ & $/ 024$ & $36 / 899$ & - & $\mathrm{q} 65$ & $<---$ & SS & $/ 869$ & $/ 021$ & $44 / 160$ & - \\
\hline $\mathrm{q} 25$ & $<---$ & S.A & $/ 817$ & & & & q66 & $<---$ & A.R & $/ 848$ & & & \\
\hline q24 & $<---$ & S.A & 1829 & $/ 026$ & $34 / 181$ & - & q67 & $<---$ & A.R & $/ 826$ & $/ 026$ & $35 / 851$ & - \\
\hline q23 & $<---$ & S.A & $/ 813$ & $/ 021$ & $33 / 203$ & - & q68 & $<---$ & A.R & $/ 838$ & $/ 028$ & $36 / 729$ & - \\
\hline q22 & $<---$ & S.A & $/ 849$ & $/ 024$ & $35 / 401$ & - & q69 & $<---$ & A.R & $/ 819$ & $/ 026$ & $35 / 338$ & - \\
\hline q21 & $<---$ & S.A & $/ 852$ & $/ 027$ & $35 / 566$ & - & q70 & $<---$ & A.R & $/ 842$ & $/ 026$ & $37 / 067$ & - \\
\hline q26 & $<---$ & D.I & $/ 838$ & & & & q71 & $<---$ & N.P & $/ 899$ & & & \\
\hline q27 & $<---$ & D.I & $/ 883$ & $/ 030$ & $39 / 908$ & - & q72 & $<---$ & N.P & $/ 874$ & $/ 019$ & $45 / 603$ & - \\
\hline q28 & $<---$ & D.I & $/ 865$ & $/ 034$ & $38 / 541$ & - & q73 & $<---$ & N.P & $/ 875$ & $/ 019$ & $45 / 839$ & - \\
\hline q29 & $<---$ & D.I & 1880 & $/ 028$ & $39 / 672$ & - & q74 & $<---$ & N.P & $/ 872$ & $/ 020$ & $45 / 412$ & - \\
\hline q30 & $<---$ & D.I & $/ 885$ & $/ 030$ & $40 / 062$ & - & q75 & $<---$ & N.P & $/ 850$ & $/ 018$ & $42 / 914$ & - \\
\hline q31 & $<---$ & VH & 1865 & & & & q76 & $<---$ & EI & $/ 868$ & & & \\
\hline q32 & $<---$ & VH & $/ 844$ & $/ 026$ & $39 / 021$ & - & q77 & $<---$ & EI & $/ 872$ & $/ 023$ & $42 / 189$ & - \\
\hline q33 & $<---$ & $\mathrm{VH}$ & $/ 810$ & $/ 028$ & $36 / 282$ & - & q78 & $<---$ & EI & $/ 903$ & $/ 023$ & $45 / 489$ & - \\
\hline q34 & $<---$ & $\mathrm{VH}$ & $/ 782$ & $/ 021$ & $34 / 192$ & - & q79 & $<---$ & EI & $/ 896$ & $/ 023$ & $44 / 736$ & - \\
\hline q35 & $<---$ & VH & $/ 858$ & $/ 023$ & $40 / 328$ & - & q80 & $<---$ & EI & $/ 910$ & $/ 023$ & $46 / 188$ & - \\
\hline q36 & $<---$ & E.U & $/ 849$ & & & & q81 & $<---$ & U.H & $/ 904$ & & & \\
\hline q37 & $<---$ & E.U & $/ 845$ & $/ 026$ & $37 / 637$ & - & q82 & $<---$ & U.H & $/ 902$ & $/ 019$ & $50 / 217$ & - \\
\hline q38 & $<---$ & E.U & $/ 819$ & $/ 023$ & $35 / 693$ & - & q83 & $<---$ & U.H & $/ 882$ & $/ 021$ & $47 / 366$ & - \\
\hline q39 & $<--$ & E.U & $/ 834$ & $/ 028$ & $36 / 797$ & - & q84 & $<---$ & U.H & $/ 892$ & $/ 019$ & $48 / 654$ & - \\
\hline q40 & $<---$ & E.U & $/ 795$ & $/ 026$ & $34 / 006$ & - & q85 & $<---$ & U.H & $/ 889$ & $/ 020$ & $48 / 271$ & - \\
\hline q41 & $<---$ & FA & 1855 & & & & q86 & $<---$ & $\mathrm{PU}$ & $/ 886$ & & & \\
\hline q42 & $<---$ & FA & $/ 802$ & $/ 030$ & $34 / 899$ & - & q87 & $<---$ & PU & $/ 882$ & $/ 023$ & $44 / 787$ & - \\
\hline q43 & $<---$ & FA & $/ 834$ & 1026 & $37 / 223$ & - & q88 & $<---$ & PU & $/ 862$ & $/ 022$ & $42 / 607$ & - \\
\hline q44 & $<---$ & FA & 1835 & $/ 025$ & $37 / 335$ & - & q89 & $<---$ & PU & $/ 848$ & $/ 023$ & $41 / 182$ & - \\
\hline q45 & $<---$ & FA & $/ 832$ & $/ 023$ & $37 / 115$ & - & q90 & $<---$ & PU & $/ 757$ & $/ 019$ & $33 / 328$ & - \\
\hline
\end{tabular}

Since CR rate is higher than $1 / 96$ and considering that level of significance is lower than $0 / 05$, all questionnaire items explain and measure significantly their latent variables. Results of second order Confirmatory Factor Analysis are in table 4. 
Table 4. Second order Confirmatory Factor Analysis.

\begin{tabular}{|c|c|c|c|c|c|c|}
\hline & & & Estimate & S.E. & C.R. & $\mathbf{P}$ \\
\hline N.P & $<--$ & O.I & /968 & /028 & $39 / 627$ & - \\
\hline EI & $<---$ & O.I & /959 & & & \\
\hline U.H & $<--$ & O.I & /965 & $/ 026$ & $39 / 783$ & - \\
\hline PU & $<--$ & O.I & /959 & $/ 026$ & $38 / 037$ & - \\
\hline A.I & $<---$ & D.R & 1928 & 1028 & $32 / 415$ & - \\
\hline M.A & $<---$ & D.R & $/ 917$ & $/ 029$ & $31 / 114$ & - \\
\hline $\mathrm{ED}$ & $<---$ & D.R & $/ 961$ & & & \\
\hline D.S & $<--$ & D.R & /974 & /027 & $35 / 000$ & - \\
\hline S.A & $<---$ & D.R & $/ 941$ & $/ 028$ & $31 / 949$ & - \\
\hline E.G & $<---$ & IL & $/ 920$ & & & \\
\hline I.S & $<--$ & IL & /926 & $/ 033$ & $29 / 062$ & - \\
\hline D.I & $<--$ & I.P & /942 & $/ 024$ & $32 / 917$ & - \\
\hline VH & $<--$ & I.P & /979 & /026 & $36 / 016$ & - \\
\hline E.U & $<--$ & I.P & /960 & & & \\
\hline FA & $<---$ & I.P & /966 & /028 & $34 / 755$ & - \\
\hline SU & $<---$ & OD & /950 & /028 & $36 / 010$ & - \\
\hline SS & $<--$ & OD & /927 & & & \\
\hline A.R & $<---$ & OD & /935 & $/ 027$ & $33 / 651$ & - \\
\hline
\end{tabular}

Since CR rate is higher than $1 / 96$ and considering that level of significance is lower than $0 / 05,18$ variables under study explain and measure significantly 5 latent variables including Disconnection and Rejection, Impaired Autonomy and Performance, Impaired Limits, Other-Directedness, and Over vigilance and Inhibition. Results of third order Confirmatory Factor Analysis are in table 5.

Table 5. Third order Confirmatory Factor Analysis.

\begin{tabular}{llllll}
\hline & & & Estimate & S.E. & C.R. \\
\hline IL & $<--$ & Co.Sch & $/ 921$ & $/ 036$ & $28 / 520$ \\
OD & $<--$ & Co.Sch & $/ 944$ & $/ 037$ & $32 / 972$ \\
I.P & $<---$ & Co.Sch & $/ 829$ & $/ 034$ & - \\
D.R & $<---$ & Co.Sch & $/ 795$ & $/ 035$ & - \\
O.I & $<---$ & Co.Sch & $/ 963$ & $/ 035$ & $28 / 143$ \\
\hline
\end{tabular}

Since CR rate is higher than $1 / 96$ and considering that level of significance is lower than $0 / 05,5$ variables including Disconnection and Rejection Impaired Autonomy and Performance, Impaired Limits, Other-Directedness and Over vigilance and Inhibition explain and measure significantly $\mathrm{Co}$.Sch as latent variables. Mentioned variables explain Co.Sch variable with factorial loads including $0.921,0.944,0.829,0.795$ and 0.963 respectively. Table 6 showing the results of model.

Table 6. Indices of model fitting.

\begin{tabular}{|c|c|c|c|c|c|c|}
\hline Model & CMIN/DF & NFI Delta1 & RFI rho1 & IFI Delta2 & TLI rho2 & CFI \\
\hline Default model & $2 / 131$ & $/ 915$ & $/ 872$ & $/ 953$ & $/ 928$ & 1952 \\
\hline
\end{tabular}

\section{Discussion}

The relative chi-square divided by the degrees of freedom is good standard for the model and supporting data. Criterion for acceptance of this index ranges from 1 to 5 which values near to 2 to 3 are explained as best values. Schumacker \& Lomax defined 1-5 values for fit index while Mclv, \& Carmines believed values in 2-3 range are acceptable. Owlman in 2001 accepted 1-2 range as good value and Cline in 2005 assumed 1-3 as acceptable variables. In above table 2/131 is reported as Chi square which can be considered as acceptable variable. NFI value or normed fit index of Bentler and Bount was obtained 0/915 which is considered as good value based on 0/9 standard value. Therefore, this model is approved and it is fit. RFI value of relative fit index is $0 / 872$ which is considered as relative fit according to $0 / 90$ as standard value. IFI value or incremental fit index is $0 / 953$ which approves goodness of fit. TLI value of talkler- Louis was $0 / 928$ which considering $0 / 90$ as standard fit approved goodness of fit. CFI value or comparative fit index is 0/952 which is good fit considering standard value of $0 / 90$.

The results of the study showed that due to the Cronbach's alpha that is higher than 0.7 , the reliability of all variables is desirable. Confirmatory factor analyses support the schema domains. We conclude that the YSQ-S3 is a psychometrically sound instrument that can be used Ukraine in research on early maladaptive schemas.

\section{Conclusion}

The present study revealed strong empirical support for the psychometric soundness of the Ukrainian version of the YSQ-S3. The instrument proved to be reliable and showed acceptable factorial validity. Schema scores were positively associated with measures of psychopathology and personality 
disorder, indicating convergent validity. The YSQ-S3 differentiated between subgroups with different levels of health-care utilization, supporting discriminant validity. All YSQ-S3 scales are associated with self-rated general psychopathology, personality disorder severity, and health care utilization. Furthermore, YSQ-S3 scales are highly interrelated. These results raise questions regarding the specificity of the schema constructs, i.e., whether different schemas can indeed be regarded as different constructs [11], and/or whether they can be grouped in a hierarchical structure [12]. Schema theory suggests five higher-order schema domain however, the validity of schema domains is currently being discussed [13]. At first glance, global fit indexes are inconclusive in confirmatory factor analysis.

\section{References}

[1] Young, J. E., Klosko J. S. \& Weishaar M. E. (2003). Schema Therapy a Practitioner's guid. New York: Guilford Press. https://www.amazon.com/Schema-Therapy-PractitionersJeffrey.../dp/1593853726.

[2] Farrell, J. M, Shaw, I. A., \& Webber, M. A. (2009). A schemafocused approach to group psychotherapy for outpatients with borderline personality disorder: A randomized controlled trial. Journal of Behavior Therapy and Experimental Psychiatry, 40, $317-328$.

[3] Giessen-Bloo, J, van Dyck, R., Spinhoven, P, van Tilburg, W, Dirksen, C, van Asselt, T., Arntz, A.

[4] Gude, T., \& Hoffart, A. (2008). Change in inter personal problems after cognitive agoraphobia and schema-focused therapy versus psychodynamic treatment as usual of inpatients with agoraphobia and cluster $\mathrm{C}$ personality disorders. Scandinavian Journal of Psychology, 49, 195-199.

[5] Nadort, M., Arntz, A., Smit, J. H., Giessen-Bloo, J, Eikelenboom, M., Spinhoven, P., van Dyck, R. (2009). Implementation of outpatient schema therapy for borderline personality disorder with versus without crisis support by the therapist outside office hours: A randomized trial. Behavior Research and Therapy, 47, 961-973.

[6] Nordahl, H. M, \& Nysaeter, T. E. (2005). Schema therapy for patients with borderline personality disorder: A single case series. Journal of Behavior Therapy and Experimental Psychiatry, 36, 254-264.

[7] Schmidt, N. B., Joiner, T. E., Young, J. E., \& Telch, M. J. (1995). The Schema Questionnaire: Investigation of psychometric properties and the hierarchical structure of maladaptive schemas. Cognitive Therapy and Research, 19, 295-321.

[8] Young, J. E. (2005). Young Schema Questionnaire - Short Form 3 (YSQ-S3). New York, NY: Cognitive Therapy Center.

[9] Beckley, K. (2007). Shema Therapy. Contemporary Psychotherapy. http://contemporarypsychotherapy.org/vol-2no-2/schema-theray/

[10] Young, J. E. (2006). Young Schema Questionnaire (German version, YSQ-S3) (H. Berbalk, J. Grutschpalk, E. Parfy, \& G. Zarbock, Trans.). Eckernförde: Institut für Schematherapie.

[11] Kriston, L., Schäfer, J, Härter, M., \& Hölzel, L. (2010, July). All the same? Factorial structure of the Young Schema Questionnaire - Short Form 3 (YSQ-S3). Paper presented at the $4^{\text {th }}$ Annual International Society of Schema Therapy Meeting, Berlin, Germany.

[12] Rijo, D, \& Gouveia, P. (2008, October). A confirmatory factor analysis study of the YSQ-S3 in a large Portuguese sample. Paper presented at the 3rd Annual International Society of Schema Therapy Meeting, Coimbra, Portugal.

[13] Lockwood, G. (2011, February 12). Do schema domain sexist? [Onlineblog]. Retrieved from http://www.isstonline.com/node $/ 226$

[14] Cudeck, R (1989). Analysis of correlation matrices using covariance structure models. Psychological Bulletin, 105, 317-327. Derogatis, L. R. (1992). The SCL-90-R, administration, scoring and procedures manual (2nd Ed.). Towson, MD: Clinical Psychometric Research.

[15] Hair, J. F., Black, W. C., Babin, B. J., \& Anderson, R. E. (2009). Multivariate data analysis (7th Ed.). Upper Saddle River, NJ: Prentice Hall

[16] Young J., 1990. Cognitive therapy of schema-oriented personality disorders. Translated by Sahebi A and Hamidpour H. Tehran: Arjmand publications.

[17] Young, J. E., \& Lindemann, M. (1992). An integrative schema-focused model for personality disorders. In Journal of Cognitive Psychotherapy. https://www.researchgate.net/.../290800082_An_integrative_s chema-focused_model_for.

[18] Young, J. E. (1999). Cognitive Therapy for personality disorders: A Schema Focused approach. Sarasota, FL: Professional Resourse Press. https://www.amazon.com/Cognitive-Therapy-PersonalityDisorders-Schema-Focused/...

[19] Young, J. E., Klosko, J. S., \& Weishaar, M. (2003). Schema therapy: A practitioner's guide. New York: Guilford. 